\title{
Setting new targets in the fight against tuberculosis
}

To the Editor:

A recent article published by Nature Medicine $(19,115,2013)$ on future, post-2015 global targets for tuberculosis (commonly called TB) control mentioned the potential of clashing among experts who were about to convene in Geneva in early February at the behest of the World Health Organization (WHO). In the article, particular emphasis was put on the possibility of a target of $50 \%$ reduction in death from this disease by 2025 as compared to 2015 levels. This target was one among several proposed and debated during the November 2012 Union World Conference on Lung Health in Kuala Lumpur, Malaysia. The idea of a $50 \%$ target did not receive strong support by some experts as it was considered insufficiently ambitious to stimulate proper mobilization of resources and action by countries and international institutions.

The WHO and the Stop TB Partnership decided, therefore, to call a consultation in Geneva as part of a series that focuses on the development of the post-2015 global tuberculosis strategy and targets for member states to consider at the 2014 World Health Assembly. The WHO workshop participants who met on 7 and 8 February shared, above all, the aspirational goal of "zero TB deaths, zero TB disease and zero suffering." There was broad agreement on a proposed set of interim targets for the year 2025 on the path of meeting this goal. The first proposed interim target is to reduce tuberculosis deaths by $75 \%$ by 2025 compared with 2015 , which would mean a decrease from a projected 1.2 million tuberculosis deaths in 2015 to 300,000 in 2025, thus saving millions of human lives. The second proposed interim target, which is closely related to and a determinant of the first one, is to reduce the tuberculosis incidence rate by $40 \%$ in the same timeframe. In addition, a bold 2025 target linked to universal health coverage, to reach "zero catastrophic expenditure for families affected by TB by 2025," was proposed.

To achieve these targets, a rapid acceleration in the reduction of tuberculosis incidence and mortality will be necessary, through implementation of several key interventions. These include much increased commitment and financing for rapid scale-up of available diagnostic and treatment measures, accelerated adoption of the newest and most effective technological advances to endemic settings, and progress in pursuing universal health coverage and social protection mechanisms coupled with economic development and poverty reduction. The participants also agreed that further dramatic progress is possible after 2025 if massive new investments are made now for the development of new tools such as innovative point-of-care diagnostics, much shorter and more effective treatment regimens and a potent vaccine that is readily available in countries where tuberculosis is endemic.

The current Stop TB Partnership target date for tuberculosis elimination is 2050 . But further work will be necessary to determine targets for 2030 and 2040 that might take the world to full tuberculosis elimination earlier. Further scientific and strategic meetings will be held to build consensus for-and ensure full commitment to-a new vision for tuberculosis control and elimination by a wide array of stakeholders. This vision will also be at the core of the Stop TB Partnership's next global plan to eliminate tuberculosis.

\section{COMPETING FINANCIAL INTERESTS}

The authors declare no competing financial interests.

Mario C Raviglione ${ }^{1}$ \& Lucica Ditiu ${ }^{2}$

${ }^{1}$ Stop TB Department, World Health Organization, Geneva, Switzerland. ${ }^{2}$ Stop TB Partnership Secretariat, Geneva, Switzerland.

e-mail: raviglionem@who.int 